\title{
Postischemic administration of angiotensin II type 1 receptor blocker reduces cerebral infarction size in hypertensive rats
}

\author{
Emi Omura-Matsuoka, Yoshiki Yagita, Tsutomu Sasaki, Yasukazu Terasaki, Naoki Oyama, Yukio Sugiyama, \\ Shuhei Okazaki, Saburo Sakoda and Kazuo Kitagawa
}

Lowering the blood pressure (BP) during the acute period following ischemic stroke is still a controversial treatment. In this study, we investigated the effect of postischemic treatment using the angiotensin II type 1 receptor blocker, candesartan, on brain damage in focal cerebral ischemia. Spontaneously hypertensive rats underwent transient occlusion of the middle cerebral artery for $1 \mathrm{~h}$. Candesartan $\left(0.1,1\right.$ and $\left.10 \mathrm{mg} \mathrm{kg}^{-1}\right)$ or vehicle was administered orally 3 and $24 \mathrm{~h}$ after ischemia. Blood pressure and neurological function were monitored, and infarct volume was evaluated $48 \mathrm{~h}$ after occlusion. Cerebral blood flow was measured using laser Doppler flowmetry before and after treatment with candesartan. Activation of Rho-kinase in cerebral microvessels was evaluated by immunohistochemistry. Systolic blood pressure was markedly lowered with both moderate and high doses, but it did not fall with a low dose of candesartan. The infarct volume was reduced in rats treated with the low dose of candesartan but not in those treated with the moderate or high doses. Cerebral blood flow decreased in parallel with the reduction in BP $3 \mathrm{~h}$ after treatment using the moderate dose, but it did not change after treatment with the low dose of candesartan, compared with vehicle. Rho-kinase was activated in the brain vessels of the ischemic cortex, but treatment with candesartan suppressed it. Our results show that oral administration of candesartan after transient focal ischemia reduced infarct volume at doses that showed little effect on BP. The neurovascular protective effects of candesartan may be caused by the inhibition of Rho-kinase in brain microvessels.

Hypertension Research (2009) 32, 548-553; doi:10.1038/hr.2009.69; published online 8 May 2009

Keywords: angiotensin II type 1 receptor antagonist; cerebral blood flow; focal cerebral ischemia; Rho-kinase

\section{INTRODUCTION}

Hypertension is one of the major risk factors of stroke. In the acute phase of stroke, blood pressure (BP) is often elevated, so patients with hypertension have a higher risk of early death, cerebral edema, and stroke recurrence. However, treatment by lowering the BP in the acute phase of ischemic stroke has been controversial. ${ }^{1}$

In experimental animal stroke models, recent studies have shown that postischemic administration of an angiotensin II type 1 receptor $\left(\mathrm{AT}_{1}\right)$ blocker $(\mathrm{ARB})$ after transient middle cerebral artery (MCA) occlusion improves neurological outcomes and reduces infarct size. ${ }^{2-5}$ However, it remains unclear whether the beneficial effects of ARBs are dose dependent. Several studies have suggested that high doses of ARBs are not beneficial because they cause hypotension. ${ }^{5,6}$

Molecular mechanisms underlying the protective effects of ARBs on the postischemic brain could include the suppression of inflammation, ${ }^{3,7-9}$ oxidative stress, ${ }^{10}$ and apoptosis. ${ }^{11}$ Recently, Rho-kinase has attracted attention because it is a potential target for the attenuation of ischemic brain injury. ${ }^{12,13}$ We have demonstrated earlier that endo- thelial Rho-kinase was activated in the ischemic cortex after MCA occlusion. ${ }^{14}$ Although intracellular signaling through the $\mathrm{AT}_{1}$ receptor is closely associated with the activation of Rho-kinase in the field of vascular biology, ${ }^{15}$ the effect of ARBs on Rho-kinase activity has not been examined in the ischemic brain.

In this study, we evaluated the dose-dependent effects of orally administered candesartan after focal cerebral ischemia in spontaneously hypertensive rats (SHR) on infarct size in relation to changes in BP and cerebral blood flow. We also examined the effect of candesartan on Rho-kinase activity in brain microvessels.

\section{METHODS}

Adult male, spontaneously hypertensive rats (Charles River Inc., Yokohama, Japan) weighing $250-350 \mathrm{~g}$ (10-15 weeks old) were used in this study. The experimental protocol was approved by the Institutional Animal Care and Use Committee of Osaka University Graduate School of Medicine. The rats were fed standard laboratory chow and had free access to water before and after all procedures. 


\section{Experiment 1}

Surgical procedure. Each animal ( $n=48$ in total, $n=12$ per group) was anesthetized with halothane, and occlusion of the left MCA was accomplished according to the procedure used by Koizumi et al. ${ }^{16}$ and Longa et al. ${ }^{17}$ (Figure 1). Briefly, the left common carotid artery was exposed by a midline incision, and the internal carotid artery was isolated and carefully separated. A 4-0 nylon monofilament, whose tip was rounded by heating, was introduced from the bifurcation of the internal carotid artery and advanced until resistance was felt. At $60 \mathrm{~min}$ after MCA occlusion, the filament was withdrawn to allow reperfusion. The animals recovered rapidly from anesthesia and were observed postoperatively for $48 \mathrm{~h}$. Rectal temperature was monitored routinely during the surgical procedure to ensure that it was maintained at $37.0 \pm 0.5^{\circ} \mathrm{C}$.

Administration of drugs and measurement of blood pressure. Vehicle $(n=12)$ or candesartan ( $n=12$ per group) was given orally using gavage twice ( 3 and $24 \mathrm{~h}$ after MCA occlusion), at three different doses $(0.1,1$, and $\left.10 \mathrm{mg} \mathrm{kg}^{-1}\right)$. We measured arterial BP in conscious rats by the tail-cuff method before ischemia and at 3, 6, 24, and $48 \mathrm{~h}$ after ischemia.

Determination of neurological deficits. Evaluation of neurological deficits was carried out before ischemia and at $3,6,24$, and $48 \mathrm{~h}$ after ischemia. Neurological findings were scored on a 5 -point scale: ${ }^{17} 0$ indicating no neurologic deficit; 1 , failure to extend the left and/or right forepaw fully; 2 , circling to the right; 3 , falling to the right; and 4 , inability to walk and a depressed level of consciousness.

Measurement of infarct volume. At $48 \mathrm{~h}$ after MCA occlusion, rats were killed with an overdose of halothane. The brain was rapidly and carefully removed, cooled in ice-cold saline for $5 \mathrm{~min}$, and then dissected into coronal 2-mm sections by using a rat brain matrix (Muromachi Kikai Co. Ltd, Tokyo, Japan). For the delineation of infarct area, the brain slices were incubated in saline containing $2 \%$ 2,3,5-triphenyltetrazolium chloride (TTC) at $37^{\circ} \mathrm{C}$ for $30 \mathrm{~min}$ and stored in $10 \%$ neutral buffered formalin. ${ }^{18}$ The ischemic lesions with no reaction towards TTC were measured on the posterior surface of each slice. The volume of ischemic lesions was measured by using an MCID image analysis system (Imaging Research Inc., St Catharines, Ontario, Canada). The area with ischemic lesions and the area of both hemispheres $\left(\mathrm{mm}^{2}\right)$ were calculated on TTC-stained coronal sections by tracing these areas on the

\section{Experiment 1}
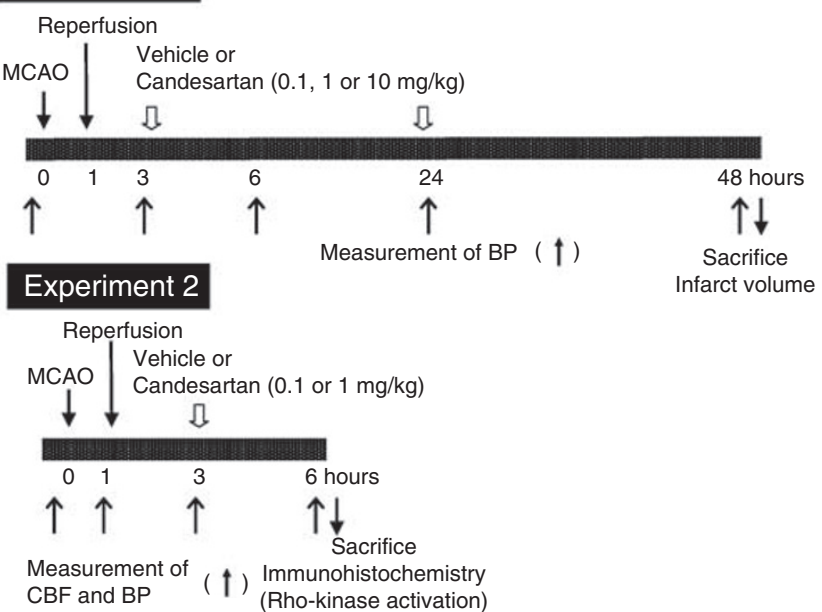

Figure 1 Experimental protocols. (Experiment 1) Vehicle or candesartan $\left(0.1,1\right.$, or $\left.10 \mathrm{mg} \mathrm{kg}^{-1}\right)$ was applied 3 and $24 \mathrm{~h}$ after middle cerebral artery occlusion (MCAO). Systolic blood pressure (BP) and neurological deficits were evaluated before ischemia and at $3,6,24$, and $48 \mathrm{~h}$ after ischemia. (Experiment 2) Vehicle or candesartan ( 0.1 or $1 \mathrm{mg} \mathrm{kg}^{-1}$ ) was applied $3 \mathrm{~h}$ after MCAO. Systolic BP and cerebral blood flow were evaluated before ischemia and at 1,3 , and $6 \mathrm{~h}$ after ischemia. computer screen. The volume $\left(\mathrm{mm}^{3}\right)$ was determined by integrating the appropriate area and the section thickness. To reduce errors associated with processing of tissue for histological evaluation, the lesion area and volume were corrected using the method of Swanson et al. ${ }^{19}$

\section{Experiment 2}

Measurement of cerebral blood flow. General anesthesia was induced using $4.0 \%$ halothane and maintained with $0.5 \%$ halothane with an open facemask (Figure 1). A polyacrylamide column with an inner diameter of $0.8 \mathrm{~mm}$, for the measurement of cortical microperfusion by laser Doppler flowmetry (Laser Doppler Blood Flow Meter, model TBF-LNIT; Unique Medical Co. Ltd. Tokyo, Japan), was attached with dental cement to the intact skull at $1 \mathrm{~mm}$ posterior to the bregma and $5 \mathrm{~mm}$ from the midline. Animals received left MCA occlusion and reperfusion $60 \mathrm{~min}$ later, and we measured the ipsilateral regional cerebral blood flow (rCBF) before and after MCA occlusion and after reperfusion under anesthesia to confirm ischemia and reperfusion. At $3 \mathrm{~h}$ after MCA occlusion, rats recovered fully from anesthesia, and their blood pressure (BP) and $\mathrm{rCBF}$ were evaluated. Then, vehicle $(n=5)$ or candesartan at $0.1 \mathrm{mg} \mathrm{kg}^{-1}(n=5)$ or $1 \mathrm{mg} \mathrm{kg}^{-1}(n=5)$ was given orally using a gavage. After $3 \mathrm{~h}, \mathrm{BP}$ and $\mathrm{rCBF}$ were measured again. The value of $\mathrm{rCBF}$ was expressed as percentage of the rCBF measured before treatment with candesartan or vehicle. Laser Doppler flowmetry, though not quantitative, provides a reliable estimate of rCBF.

Immunohistochemistry. After evaluation of $\mathrm{BP}$ and $\mathrm{rCBF}$, animals were perfused transcardially with Zamboni's solution (2\% paraformaldehyde, $0.2 \%$ picric acid), and brains were postfixed in the same fixative overnight at $4{ }^{\circ} \mathrm{C}$. Brains were cut into frozen $10-\mu \mathrm{m}$-thick coronal sections, non-specific staining was blocked with $10 \%$ normal serum (Vector Laboratories, Burlingame, CA, USA), and the sections were incubated with the primary antibodies, anti-padducin (Santa Cruz Biotechnology, Santa Cruz, CA, USA) and anti-p-MYPT1 (myosin phosphatase target subunit 1) (CycLex Co. Ltd, Nagano, Japan). Adducin and MYPT1 are specific Rho-kinase substrates, ${ }^{20}$ and increased phosphorylation of adducin or MYPT1 is related to Rho-kinase activation. The ABC Elite kit (Vector Laboratories, Burlingame, CA, USA) was used after sections were incubated with the appropriate biotinylated secondary antibody.

Statistical analysis. All values reported here are expressed as means \pm standard deviation (s.d.). Statistical comparisons among groups were carried out using one-way analysis of variance (ANOVA) with the Bonferroni-Dunn post-hoc test using SPSS version 9J (SPSS Japan Inc., Tokyo, Japan). For all procedures, $P$-values $<0.05$ were considered statistically significant.

\section{RESULTS}

Effects of drug treatments on blood pressure and body temperature In SHRs subjected to transient MCA occlusion, treatment with 1 and $10 \mathrm{mg} \mathrm{kg}^{-1}$ candesartan significantly reduced the systolic blood pressure (SBP) as early as $3 \mathrm{~h}$ after administration compared with vehicle, and the reduction was maintained until $21 \mathrm{~h}$ after treatment and was more pronounced $24 \mathrm{~h}$ after the second administration in a dosedependent manner (Table 1). There was no significant difference in BP between the $0.1 \mathrm{mg} \mathrm{kg}^{-1}$ candesartan and vehicle groups. There was no difference in body temperature between the treatment groups (Table 1)

\section{Ischemic lesions and neurological scores}

In the vehicle group, $48 \mathrm{~h}$ after $1-\mathrm{h}$ MCA occlusion, lesion areas of the brain extended to the entire MCA territory, including the cerebral cortex and caudoputamen (Figure 2a). The total lesion volume was significantly smaller in rats treated with candesartan at a dose of $0.1 \mathrm{mg} \mathrm{kg}^{-1}$ than in those treated with vehicle (109.6 $\pm 86.6 \mathrm{vs}$. $234.9 \pm 59.1 \mathrm{~mm}^{3} ; P<0.05$ ) (Figures $2 \mathrm{~b}$ and $3 \mathrm{a}$ ). There was no difference in lesion size between rats treated with 1 or $10 \mathrm{mg} \mathrm{kg}^{-1}$ candesartan and vehicle-treated rats (Figures 2 and 3a). The 
Table 1 Change of systolic blood pressures and body temperatures

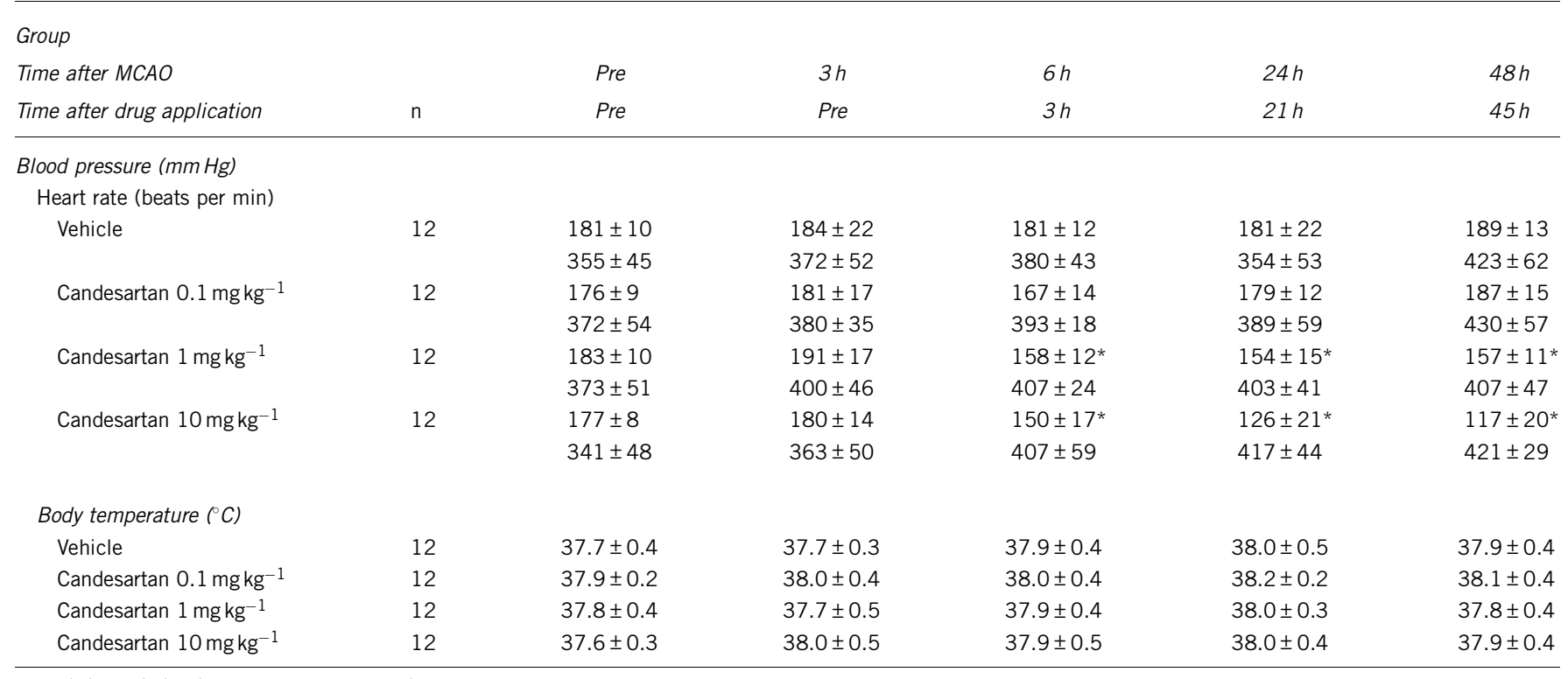

Abbreviation: MCAO, middle cerebral artery occlusion. Values are the mean \pm s.d.

The significance of differences was determined using ANOVA followed by Bonferroni's post hoc tests. $* P<0.05$ compared with the vehicle group.

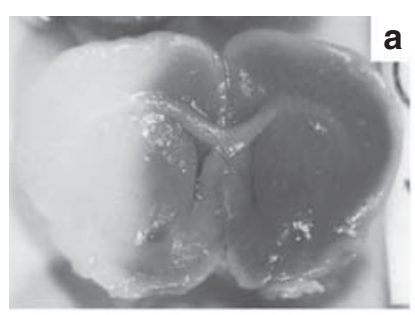

Vehicle

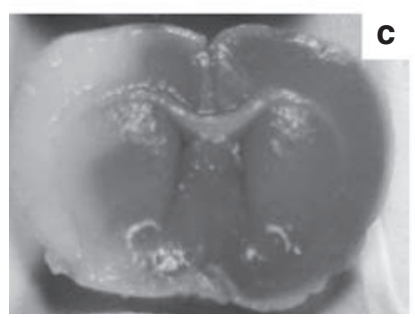

Candesartan $1 \mathrm{mg} / \mathrm{kg}$

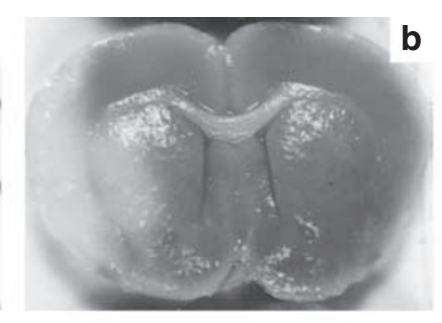

Candesartan $0.1 \mathrm{mg} / \mathrm{kg}$

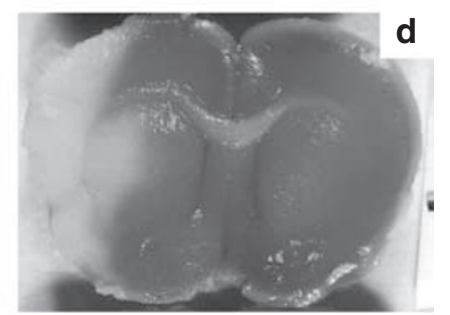

Candesartan $10 \mathrm{mg} / \mathrm{kg}$
Figure 2 Representative 2,3,5-triphenyltetrazolium chloride staining of the brain $48 \mathrm{~h}$ after middle cerebral artery (MCA) occlusion for $1 \mathrm{~h}$. In the rats treated with vehicle, infarct was visible in the entire MCA territory (a). However, a smaller infarct area was observed in the rats treated with $0.1 \mathrm{mg} \mathrm{kg}^{-1}$ candesartan (b). In the rats treated with $1 \mathrm{mg} \mathrm{kg}^{-1}$ (c) or $10 \mathrm{mg} \mathrm{kg}^{-1}$ (d) candesartan, the size of infarct was similar to that in vehicle treatment.

neurological score improved in a time-dependent manner (Figure 3b), but there were no significant differences among the treatment groups.

Change of cerebral blood flow after drug administration

MCA occlusion decreased the ipsilateral rCBF to $20 \%$ of baseline, and reperfusion recovered $\mathrm{rCBF}$ to baseline under anesthesia in all groups.
At $3 \mathrm{~h}$ after MCA occlusion, the animals were fully awake, and the SBP was about $200 \mathrm{~mm} \mathrm{Hg}$. At $3 \mathrm{~h}$ after administration of $1 \mathrm{mg} \mathrm{kg}^{-1}$ candesartan, the SBP fell to $172 \mathrm{~mm} \mathrm{Hg}$. Ipsilateral rCBF expressed as a percent of the values before drug treatment also significantly decreased compared with the vehicle group (Figure 4). In contrast, treatment with $0.1 \mathrm{mg} \mathrm{kg}^{-1}$ candesartan showed no change in SBP and no decrease in $\mathrm{rCBF}$ compared with the vehicle group (Figure 4).

\section{Suppression of Rho-kinase activity by candesartan}

At $6 \mathrm{~h}$ after transient MCA occlusion for $1 \mathrm{~h}$, phosphorylation of adducin ( $\mathrm{p}$-adducin) and myosin phosphatase target subunit 1 (p-MYPT1), which are specific Rho-kinase substrates, increased in brain vessels in the ipsilateral cortex (Figures $5 \mathrm{a}$ and $\mathrm{b}$ ) compared with the contralateral cortex (Figures $5 \mathrm{c}$ and $\mathrm{d}$ ). Treatment with $0.1 \mathrm{mg} \mathrm{kg}^{-1}$ candesartan attenuated the signal for $\mathrm{p}$-adducin and p-MYPT1 in brain microvessels within the ischemic hemisphere (Figures 5e and $\mathrm{f}$ ).

\section{DISCUSSION}

We show that oral administration of candesartan at a low dose $\left(0.1 \mathrm{mg} \mathrm{kg}^{-1}\right)$ starting at $3 \mathrm{~h}$ after transient MCA occlusion results in a significant reduction of infarct size without decreasing BPs in SHR. Compared with controls, infarct size in rats treated with low-dose candesartan was nearly $50 \%$ smaller. However, candesartan treatment at higher doses ( 1 or $10 \mathrm{mg} \mathrm{kg}^{-1}$ ) lowered the BP but failed to show beneficial effects on infarct size. Gohlke et al. ${ }^{21}$ have shown earlier that oral administration of $0.1 \mathrm{mg} \mathrm{kg}^{-1}$ candesartan inhibited the central response to angiotensin II. This finding is in agreement with other studies showing that postischemic low-dose, but not moderate- or high-dose, administration of candesartan is neuroprotective against transient focal ischemia in both normotensive ${ }^{5}$ and hypertensive rats. ${ }^{6}$ Furthermore, our results show that lowering the BP shortly after reperfusion in SHR results in a decline in cerebral blood flow in the affected cortex, which could overshadow any potential beneficial 
effects of ARBs. However, postischemic treatment with another ARB, olmesartan, was shown to be protective in normotensive rats at both low and high doses. ${ }^{3}$ Future study of this treatment is required to clarify whether postischemic high-dose treatment with other ARBs is protective in hypertensive rats. In clinical studies, BP reduction during the first $24 \mathrm{~h}$ after stroke onset is an independent risk factor for poor
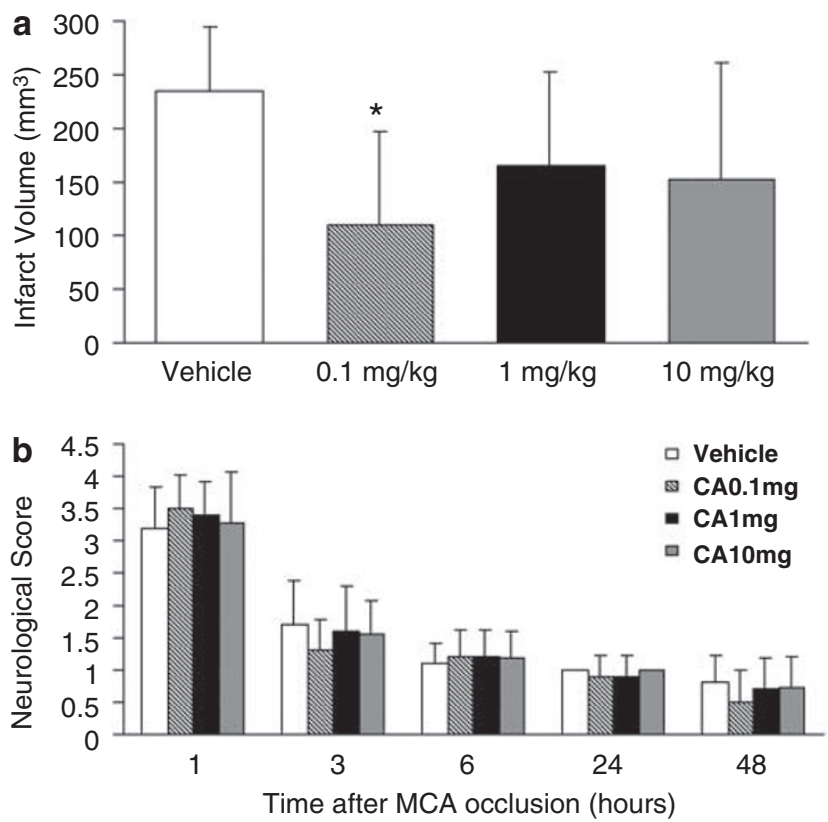

Figure 3 (a) Infarct volume after middle cerebral artery (MCA) occlusion. Treatment with candesartan (CA) at a dose of $0.1 \mathrm{mg} \mathrm{kg}^{-1}$ reduced the total lesion volume, but no significance was shown in the treatment groups at doses of 1 or $10 \mathrm{mg} \mathrm{kg}^{-1}$ compared with the vehicle group. (b) Neurological scores after MCA occlusion. Neurological findings improved in a timedependent manner after MCA occlusion, but there was no difference among treatment groups. Values are mean \pm s.d. ${ }^{*} P<0.05$ compared with the vehicle group. outcomes after acute ischemic stroke. ${ }^{22}$ The ACCESS study showed a reduction in mortality among patients with acute ischemic stroke who received candesartan within $48 \mathrm{~h}$ after onset, whereas the level of BP was similar between candesartan and placebo groups. ${ }^{23}$ Both experimental and clinical studies are likely to show that postischemic treatment with the ARB candesartan is neuroprotective only at doses with little effect on BP. It remains unclear whether other antihypertensive drugs have similar protective effects at low doses.

There are several mechanisms underlying the neuroprotective effects of ARBs in the ischemic brain. Chronic treatment with ARBs before ischemia has been shown to reverse remodeling of cerebral vessels, ${ }^{24,25}$ promote angiogenesis, ${ }^{26}$ and attenuate the severity of ischemia after vessel occlusion. However, the effects on blood flow or vascular remodeling are unlikely to explain the beneficial effects of postischemic treatment with ARBs. Besides lowering of BP and relaxation of vascular tonus, ARBs have been shown to have potentially beneficial effects such as anti-inflammatory, ${ }^{3,7-9}$ anti-oxidative, ${ }^{10}$ anti-apoptotic, ${ }^{11}$ and stimulation of angiotensin II type 2 receptors ${ }^{27}$ in cerebral ischemia models. Here, in addition to these pleiotropic effects of ARBs, we show that activation of endothelial Rho-kinase in the ischemic brain is suppressed after treatment with candesartan. In the ischemic brain of acute stroke, brain angiotensin II is upregulated, ${ }^{3}$ and stimulation of the AT1 receptor activates Rhokinase. ${ }^{15}$ Rho-kinase was identified as an effector of the small GTPase $\mathrm{rho}^{28,29}$ and was implicated in smooth-muscle contraction, cell migration, and endothelial function. ${ }^{15,30}$ In brain endothelial cells, activated Rho-kinase can cause damage to the endothelial cells and can also cause microcirculatory disturbances. ${ }^{14}$ Postischemic treatment with the Rho-kinase inhibitor fasudil inhibits the expansion of cerebral infarction. ${ }^{14}$ Our results show that administration of candesartan suppresses endothelial Rho-kinase activation. This effect may be one of the explanations for the neuroprotective effects of ARBs.

In conclusion, we show that postischemic oral administration of the ARB candesartan at doses with little effect on BP reduces infarct volume in a transient MCA occlusion model of SHR. We also show that treatment with an ARB suppresses Rho-kinase activation in brain microvessels after ischemia. The significance of the neuroprotective
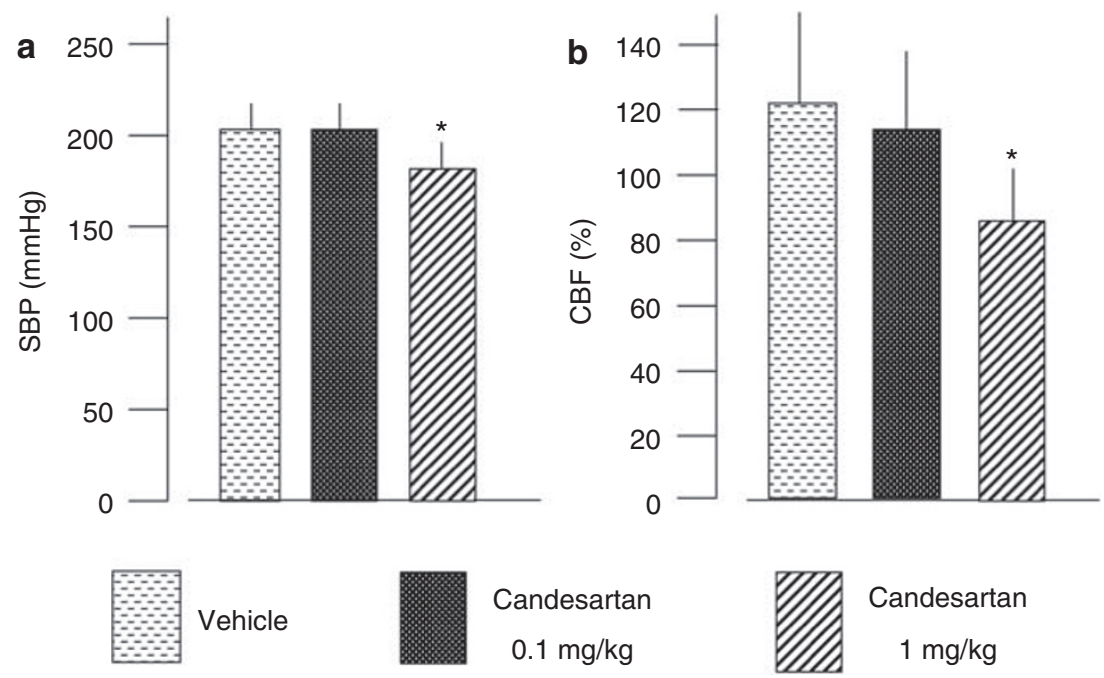

Figure 4 (a) Systolic blood pressure (SBP) after candesartan treatment. Administration of candesartan at $1 \mathrm{mg} \mathrm{kg}^{-1}$ lowered SBP from 200 to $172 \mathrm{~mm} \mathrm{Hg}$ $3 \mathrm{~h}$ later, but administration of vehicle or $0.1 \mathrm{mg} \mathrm{kg}^{-1}$ candesartan did not decrease SBP. (b) Ipsilateral regional cerebral blood flow ( $\mathrm{rCBF}$ ) changed after candesartan administration. CBF decreased $3 \mathrm{~h}$ after $1 \mathrm{mg} / \mathrm{kg}$ candesartan treatment compared with that in vehicle, but treatment with $0.1 \mathrm{mg} \mathrm{kg}^{-1}$ candesartan did not reduce CBF. Values are mean \pm s.d. ${ }^{*} P<0.05$ compared with the vehicle group. 

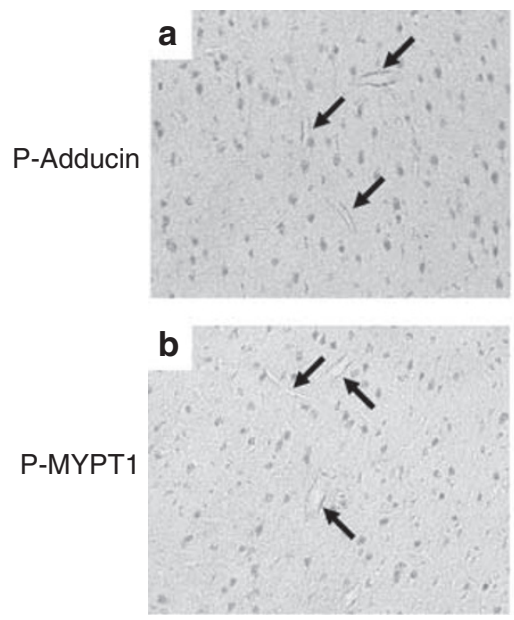

Ipsilateral cortex

(vehicle)
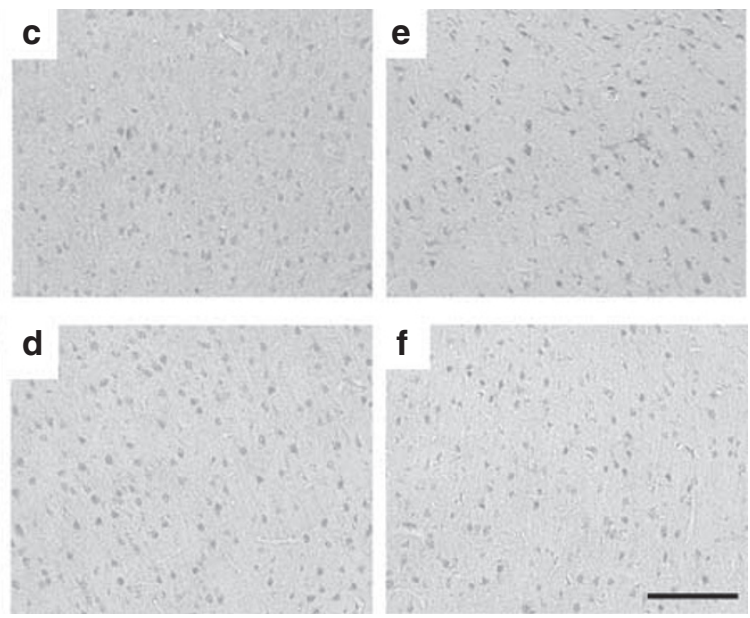

Contralateral cortex

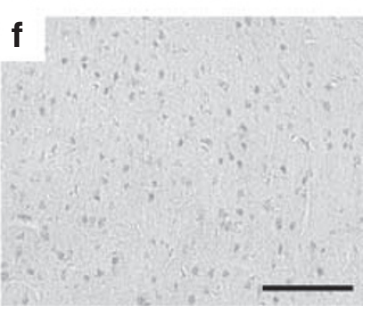

Ipsilateral cortex (candesartan $0.1 \mathrm{mg} / \mathrm{kg}$ )

Figure 5 Suppression of Rho-kinase activity in the brain vessels of ischemic cortex by candesartan treatment. Immunohistochemistry of $p$-adducin (a, $\mathbf{c}$ and e) and p-myosin phosphatase target subunit 1 (MYPT1) (b, $\mathbf{d}$ and $\mathbf{f}$ ) indicates Rho-kinase activation. At $6 \mathrm{~h}$ after middle cerebral artery occlusion (MCAO), the signals for p-adducin and p-MYPT1 were increased in brain vessels in ipsilateral cortex (arrows in $\mathbf{a}$ and $\mathbf{b}$ ) compared with those in the contralateral cortex (c and d). Decreased staining of p-adducin (e) or p-MYPT1 (f) in the ipsilateral brain vessels of rats treated with $0.1 \mathrm{mg} \mathrm{kg}^{-1} \mathrm{candesartan}$ indicated suppression of Rho-kinase activity.

action of the ARBs will have to be clarified in the future from both basic and clinical aspects.

\section{CONFLICT OF INTEREST}

The authors declare no conflict of interest.

\section{ACKNOWLEDGEMENTS}

We thank C Kurano and K Nishiyama for secretarial assistance. This work was supported in part by Grants-in-Aid for Scientific Research (C) from the Ministry of Education, Science, and Culture and Sports in Japan and was also supported in part by the Smoking Research Foundation.

1 Adams Jr HP, del Zoppo G, Alberts MJ, Bhatt DL, Brass L, Furlan A, Grubb RL, Higashida RT, Jauch EC, Kidwell C, Lyden PD, Morgenstern LB, Qureshi Al, Rosenwasser RH, Scott PA, Wijdicks EF. Guidelines for the early management of adults with ischemic stroke. Stroke 2007; 38: 1655-1711.

2 Engelhorn T, Goerike S, Doerfler A, Okorn C, Forsting M, Heusch G, Schulz R. The angiotensin II type 1-receptor blocker candesartan increases cerebral blood flow, reduces infarct size, and improves neurologic outcome after transient cerebral ischemia in rats. J Cereb Blood Flow Metab 2004; 24: 467-474.

3 Hosomi N, Nishiyama A, Ban CR, Naya T, Takahashi T, Kohno M, Koziol JA. Angiotensin type 1 receptor blockage improves ischemic injury following transient focal cerebral ischemia. Neuroscience 2005; 234: 225-231.

4 Fagan SC, Kozak A, Hill WD, Pollock DM, Xu L, Johnson MH, Ergul A, Hess DC. Hypertension after experimental cerebral ischemia: candesartan provides neurovascular protection. J Hypertens 2006; 24: 535-539.

5 Brdon J, Kaiser S, Hagemann F, Zhao Y, Culman J, Gohlke P. Comparison between early and delayed systemic treatment with candesartan of rats after ischemic stroke. $J$ Hypertens 2007; 25: 187-196.

6 Kozak W, Kozak A, Johnson MH, Elewa HF, Fagan SC. Vascular protection with candesartan after experimental acute stroke in hypertensive rats: a dose-response study. J Pharamcol Exp Ther 2008; 326: 773-782.

7 Dai WJ, Funk A, Herdegen T, Unger T, Culman J. Blockade of central angiotensin AT(1) receptors improves neurological outcome and reduces expression of AP-1 transcription factors after focal brain ischemia in rats. Stroke 1999; 30: 2391-2398.

8 Ando H, Zhou J, Macova M, Imboden H, Saavedra JM. Angiotensin II AT1 receptor blockade reverses pathological hypertrophy and inflammation in brain microvessels of spontaneously hypertensive rats. Stroke 2004; 35: 1726-1731.

9 Zhou J, Ando H, Macova M, Dou J, Saavedra JM, Imboden H. Angiotensin II AT1 receptor blockade abolishes brain microvascular inflammation and heat shock protein responses in hypertensive rats. J Cereb Blood Flow Metab 2005; 25: 878-886.
10 Iwai M, Liu HW, Chen R, Ide A, Okamoto S, Hata R, Sakanaka M, Shiuchi T, Horiuchi M. Possible inhibition of focal cerebral ischemia by angiotensin II type 2 receptor stimulation. Circulation 2004; 110: 843-848.

11 Lou M, Blume A, Zhao Y, Gohlke P, Deuschl G, Herdegen T, Culman J. Sustained blockade of brain AT1 receptors before and after focal cerebral ischemia alleviates neurologic deficits and reduces neuronal injury, apoptosis, and inflammatory responses in the rat. J Cereb Blood Flow Metab 2004; 24: 536-547.

12 Rikitake Y, Kim HH, Huang Z, Seto M, Yano K, Asano T, Moskowitz MA, Liao JK. Inhibition of Rho kinase (ROCK) leads to increased cerebral blood flow and stroke prevention. Stroke 2005; 36: 2251-2257.

13 Shin HK, Salomone S, Potts EM, Lee SW, Millican E, Noma K, Huang PL, Boas DA, Liao JK, Moskowitz MA, Ayata C. Rho-kinase inhibition acutely augments blood flow in focal cerebral ischemia via endothelial mechanisms. J Cereb Blood Flow Metab 2007; 27: 998-1009.

14 Yagita Y, Kitagawa K, Sasaki T, Terasaki Y, Todo K, Omura-Matsuoka E, Kaibuchi K, Hori M. Rho-kinase activation in endothelial cells contributes to expansion of infarction after focal cerebral ischemia. J Neurosci Res 2007; 85: 2460-2469.

15 Shimokawa H, Takeshita A. Rho-kinase is an important therapeutic target in cardiovascular medicine. Arterioscler Thromb Vasc Biol 2007; 25: 1767-1775.

16 Koizumi J, Yoshida Y, Nakazawa T, Ooneda G. Experimental studies of ischemic brain edema, I: a new experimental model of cerebral embolism in rats in which recirculation can be introduced in the ischemic area. Jpn J Stroke 1996; 8: 1-8.

17 Longa EZ, Weinstein PR, Carlson S, Cummins R. Reversible middle cerebral artery occlusion without craniectomy in rats. Stroke 1989; 20: 84-91.

18 Bederson JB, Pitts LH, Germano SM, Nishimura MC, Davis RL, Bartkowski HM. Evaluation of 2,3,5-triphenyltetrazolium chloride as a stain for detection and quantification of experimental cerebral infarction in rats. Stroke 1986; 17: 1304-1308.

19 Swanson RA, Morton MT, Tsao-Wu G, Savalos RA, Davidson C, Sharp FR. A semiautomated method for measuring brain infarct volume. J Cereb Blood Flow Metab 1990; 10: 290-293.

20 Kimura K, Fukata Y, Matsuoka Y, Bennett V, Matsuura Y, Okawa K, Iwamatsu A, Kaibuchi K. Regulation of the association of adducin with actin filaments by Rhoassociated kinase (Rho-kinase) and myosin phosphatase. J Biol Chem 1998; 273: 5542-5548.

21 Gohlke P, Von Kugelgen S, Jurgensen T, Kox T, Rascher W, Culman J, Unger T. Effects of orally applied candesartan cilexetil on central responses to angiotensin II in conscious rats. J Hypertens 2002; 20: 909-918.

22 Oliveira-Filho J, Silva SC, Trabuco CC, Pedreira BB, Sousa EU, Bacellar A. Detrimental effect of blood pressure reduction in the first $24 \mathrm{~h}$ of acute stroke onset. Neurology 2003; 61: 1047-1051.

23 Schrader J, Luders S, Kulschewski A, Berger J, Zidek W, Treib J, Einhaupl K, Diener HC, Dominiak P. The ACCESS Study: evaluation of Acute Candesartan Cilexetil Therapy in Stroke Survivors. Stroke 2003; 34: 1699-1703.

24 Nishimura Y, Ito T, Saavedra JM. Angiotensin II AT(1) blockade normalizes cerebrovascular autoregulation and reduces cerebral ischemia in spontaneously hypertensive rats. Stroke 2000; 31: 2478-2486.

25 Ito T, Yamakawa H, Bregonzio C, Terron JA, Falcon-Neri A, Saavedra JM. Protection against ischemia and improvement of cerebral blood flow in genetically hypertensive 
rats by chronic pretreatment with an angiotensin II AT1 antagonist. Stroke 2002; 33: 2297-2303.

26 Forder JP, Munzenmaier DH, Greene AS. Angiogenic protection from focal ischemia with angiotensin II type 1 receptor blockade in the rat. Am J Physiol Heart Circ Physiol 2005; 288: H1989-H1996.

$27 \mathrm{Li} \mathrm{J}$, Culman J, Hortnagl $\mathrm{H}$, Zhao $\mathrm{Y}$, Gerova $\mathrm{N}$, Timm M, Blume A, Zimmermann M, Seidel K, Dirnagl U, Unger T. Angiotensin AT2 receptor protects against cerebral ischemia-induced neuronal injury. FASEB J 2005; 19: 617-619.
28 Amano M, Mukai H, Ono Y, Chihara K, Matsui T, Hamajima Y, Okawa K, Iwamatsu A, Kaibuchi K. Identification of a putative target for Rho as the srine-theronine kinase protein kinase N. Science 1996; 271: 648-650.

29 Kimura K, Ito M, Amano M, Chihara K, Fukata Y, Nakafuku M, Yamamori B, Feng J, Nakano T, Okawa M, Iwamatsu A, Kaibuchi K. Regulation of myosin phosphatase by Rho and Rho-associated kinase (Rho-kinase). Science 1996; 273: 245-248.

30 Faraci FM, Lamping KG, Modrick ML, Ryan MJ, Sigmund CD, Didion SP. Cerebral vascular effects of angiotensin II: new insights from genetic models. J Cereb Blood Flow Metab 2006; 26: 449-455. 